\title{
ASSESSING LONG-RUN GROWTH PROSPECTS FOR THE
}

\section{UK'S REGIONS}

\author{
George Verikios \\ KPMG Australia and Department of Accounting, Finance and Economics, Griffith University \\ Ian Hurst and Garry Young \\ National Institute of Economic \& Social Research
}

\begin{abstract}
$\underline{\text { Abstract }}$
The UK faces a number of economic challenges in the short- to medium-term. Prior to COVID-19, renegotiation of trading arrangements with the European Union was the most prominent of these. We build on existing macroeconomic analysis by assessing prospects for the UK's regions generated by combining a global macroeconometric model and a regional computable general equilibrium of the UK. A central macroeconomic scenario shows a national average annual GDP growth rate of $1.7 \%$ to 2044. When the macroeconomic scenario is applied across regions growth rates range from $1.6 \%$ for Cambridge to $2.2 \%$ for Pembrokeshire; the standard deviation is low at $0.07 \%$ and the coefficient of variation is $0.04 \%$. In contrast, much wider variation is observed in the standard deviation for exports $(0.36 \%)$, investment $(0.11 \%)$ and consumption $(0.14 \%)$. The country results favour Scotland, which grows at annual rate of $1.8 \%$, whereas Wales is the slowest growing of the countries at $1.7 \%$. Consistent with the macroeconomic analysis international trade is the most important contributor to the regional variation in growth rates. We also analyse the effects of higher government consumption relative to the forecasts. Most regions are predicted to experience lower economic activity from this shock except the handful in which government consumption is a much higher share of GDP than average.
\end{abstract}

Keywords: $\quad$ computable general equilibrium, government consumption shock, economic growth, macroeconometric model, trade shocks, regional analysis.

JEL: $\quad$ E27, E37, O11, R11.

\section{Acknowledgements}

The views expressed here are the authors' and do not necessarily reflect those of KPMG, Griffith University or the National Institute Of Economic \& Social Research. We thank Kevin Hanslow, Brendan Rynne and an anonymous referee for helpful comments on the paper. 


\section{Introduction}

The United Kingdom (UK) faces a number of economic challenges in the short- to medium-term. Prior to COVID-19, the most prominent of these, given the vote to leave the EU in the referendum of 2016, was the state of future trading arrangements with the European Union (EU) and with other countries. The UK left the EU in January 2020, but the ultimate trading relationship is still to be determined. The future economic and legal relationship with the EU will affect UK trade with the EU and has significant potential for economic disruption as roughly half of all UK trade occurs with EU members. A second major medium-term challenge is the slowdown in productivity growth in the UK over the last two decades and the associated low overall labour productivity growth relative to other highincome countries. A third major challenge is the persistent and significant government budget deficit and corresponding accumulation of government debt that now stands at over $100 \%$ of GDP and has the potential to rise further.

These challenges have been analysed by the UK government and others as regards their aggregate effects on the UK economy (e.g., Behrens and Mion, 2017; Douch et al, 2017; Hantzsche et al, 2019) but there has been little research focussing on how these challenges will affect different regions of the UK. This work focusses on this issue by projecting growth outcomes for UK regions out to 2044. The projections are generated by combining two sophisticated analytical frameworks: a global macroeconometric model and a regional computable general equilibrium (CGE) of the UK.

At the macro level we apply NiGEM (National institute's Global Econometric model). NiGEM is a large model of the world economy that is used for forecasting and scenario analysis. It encompasses discrete models for most OECD economies and regional blocks for the remaining countries in Asia, America, Africa, the Middle East and Europe. The regional sub-models that make up NiGEM depend on both theory and data. There is a common (estimated and calibrated) underlying structure across all economies. The model's long-run equilibrium properties are neoclassical. That is, output is tied down in the long-run by factor inputs and technical progress interacting through production functions. In contrast, the short-term dynamic properties and underlying estimated properties are consistent with data. The model can treat agents as forward looking, as holding rational expectations or applying adaptive learning. The model is flexible in the treatment of different policy environments.

NiGEM is applied to generate a macroeconomic scenario for the UK economy out to 2044. The scenario is based on NIESR's November 2018 forecast and at that time 
encompassed all known future changes in economic variables for the UK and other major economies. The forecast also encompassed judgements on the future effects of Brexit and other economic challenges. These quarterly outcomes are converted to annual changes and subsequently applied to a regional model of the UK.

The UK regional model (UK-SCGE) is a dynamic spatial CGE model with long-run properties similar to NiGEM. The short-run behaviour is mainly characterised by the movement from an initial steady-state that is consistent with the latest input-output data, and national and regional accounts. Over time the model slowly moves from the initial steadystate along a balanced growth path to a new steady-state. The model represents 29 industries, 109 regions, 44 investment inputs for each industry, a central and local government sector with detailed government expenditure and revenue accounts. Exports and imports are specified by EU and non-EU destinations and sources. It also includes a detailed representation of the current and capital accounts, accumulation of foreign assets, foreign liabilities and government debt.

NiGEM and UK-SCGE belong to different classes of model. NiGEM is multicountry macroeconometric macro model whereas UK-SCGE is a multi-region, multi-sector CGE model of a single country. Both models are dynamic but their periodicity varies; NiGEM is a quarterly model whereas UK-SCGE is, like most dynamic CGE models, an annual model. The nature of the dynamics also varies. The dynamics of NiGEM are driven by lagged error correction around trend growth rates determined by econometric estimation. The dynamics of UK-SCGE are purely deterministic and are mostly driven by the behaviour of stock-flow relationships. Of these, the capital stock is the most important and those for financial assets less so. Applying a forecast from NiGEM to UK-SCGE thus poses challenges in reconciling divergent approaches to representing economic behaviour through time.

The NiGEM results are applied as annual inputs to the regional model. The inputs include the expenditure- and income-side components of GDP, labour productivity, price deflators (import, exports and consumer goods) and the exchange rate. This ensures that at the macro level the two models are consistent in their representation of the path of the aggregate economy. Using the macro inputs from NiGEM, the regional model generates a rich pattern of effects for 109 regions. The effects provide an internally consistent story of changes in regional output. These changes are decomposed to explain how regions are affected differentially by the various long-run trends in the UK economy that are projected by the macro model. Further, the regional results also provide a ranking of growth prospects 
across the UK regions. This ranking can provide policy makers with a view on where economic policy changes might be focussed to reduce the largest disparities in regional outcomes.

\section{The NiGEM model}

The NiGEM ${ }^{1}$ model represents the world economy. It contains 46 countries and 7 regional groupings. Most OECD countries are modelled individually. There is a common underlying structure across all economies; this structure is estimated and calibrated. The model's long-run is neoclassical. Expectations can be characterised as forward looking, rational or adaptive learning. The country models have a comprehensive representation of the demand and supply side, and asset structures. Most behavioural equations are estimated in error-correction form.

Expenditure-side GDP is defined as the familiar national accounts identity $G D P=C+I+G+X-M$. In the short- to medium-run the model is Keynesian and GDP is demand driven. In the long-run GDP is supply-side driven and related to potential output $\left(Y^{P}\right)$

$$
Y_{t}^{P}=\gamma\left\{\left[\beta K_{t}^{-\rho}+(1-\beta) L_{t}^{-\rho}\right]^{-1 / \rho}\right\}^{(1-\alpha)} M_{t}^{\alpha} .
$$

Thus, production is represented by CES technology applying capital $(K)$ and effective labour $(L)$ where $\sigma=1 /(1+\rho)$ is the elasticity of substitution between labour and capital. The capital-labour composite is combined with oil $(M)$ by a Cobb-Douglas production function with $\alpha$ as the share parameter for oil: thus, the elasticity of substitution between the labourcapital composite and oil is one. Effective labour equals actual labour $(N)$ adjusted for labour productivity $(L P)$ and the speed of adjustment per period towards the long-run $(\lambda): L=N e^{\lambda L P}$.

The first-order condition for labour defines labour demand as

$$
\ln \left(L_{t} / Q_{t}\right)=\vartheta-\sigma \ln \left(W_{t} / P_{t}\right)-(1-\sigma) \lambda L P,
$$

where $Q_{t}$ is total primary factor usage, and $P_{t}$ is the primary factor price index, being a CES aggregate of the rental price of capital $R_{t}$ and the effective wage rate $W_{t} / P_{t}$.

The first-order condition for capital defines the equilibrium capital-output ratio $\left(K_{t} / Q_{t}\right)$ as a function of the effective user cost of capital $U_{t}=\left(R_{t} / P_{t}\right)$ :

$$
\ln \left(K_{t} / Q_{t}\right)=\eta-\sigma \ln U_{t}
$$

\footnotetext{
1 National institute's Global Econometric model.
} 
The user cost of capital includes corporate taxes, depreciation and risk premia. It is a weighted average of the cost of equity finance and the long real interest rate. The supply of capital evolves as

$$
K_{t}=(1-\delta) K_{t-1}+I_{t},
$$

where $\delta$ is geometric rate of depreciation. As full capacity utilisation is not assumed, business investment is determined by the relationship between actual and equilibrium capital stocks, which is of error correction form.

Unit total cost is a function of the prices of labour, capital and oil. The wage rate is a function of unit total cost and the unemployment rate, which acts as a proxy for bargaining power for workers. Short-term wage dynamics depend on a weighted average of expected and current inflation.

Capacity utilisation $\left(Y / Y^{P}\right)$ drives producer prices so that full capacity utilisation is achieved over time. Consumer prices are a mark-up on unit total costs and import prices, adjusted for the indirect tax rate.

Consumption follows a dynamic adjustment path around real household disposable income $(R H D I)$ and the sum of real housing wealth $(R H W)$ and real financial wealth $(R F W)$ :

$$
\ln C=\phi+\beta \ln R H D I+(1-\beta) \ln (R F W+R H W) .
$$

Each country has a stock of foreign assets and liabilities. These are linked to the stock of domestic financial assets and the stock of domestic private sector and public sector liabilities. A proportion of government debt is owned abroad, as are proportions of the national stock of equities and the stock of banking assets. Some national financial wealth is held in foreign equities and bonds as well as banks. Income flows from asset stocks are allocated in relation to ownership, and hence net property income from abroad depends on income receipts and payments on bonds, equity holdings and bank. Once model and judgement-based forecasts for asset prices, exchange rates and interest rates have been made, the forecast for wealth follows automatically. The wealth and accumulation system allows for flows of saving into wealth and for revaluations of existing stocks of assets in line with their prices determined as above. When foreign equity and bond prices change, domestically held assets change in value.

The government sector is represented as raising direct and indirect taxes, undertaking consumption spending and making interest payments. A tax rule is imposed that ensures long-run solvency. Government consumption and investment have an exogenous component 
and an endogenous component. The endogenous component is linked to $Y^{P}$. The exogenous component dominates.

Exports are a function of external market size $(S)$ and relative export prices $(P X / A P X)$

$$
X=\mu+S+\kappa(P X / A P X) .
$$

where $P X$ represents export prices and $A P X$ is the weighted average of competitor export prices. Imports are a function of total final expenditure (TFE) and relative import prices $(C P / A P M)$

$$
M=\psi+v T F E+\omega(C P / A P M)
$$

where $C P$ represents consumer prices and $A P M$ is the weighted-average of export prices in import source countries.

Long-term interest rates $\left(i_{t}^{L}\right)$ are related to expected future short-term interest rates $\left(i_{t}\right)$

$$
1+i_{t}^{L}=\prod_{t=1}^{T}\left(1+i_{t+j}\right)
$$

Equity prices $(E Q P)$ reflect the present discounted value of expected profits $(P R)$, including an equity risk premium $(R P)$

$$
E Q P_{t}=\frac{E Q P_{t+1}}{1+i_{t}}+P R_{t}\left(1+R P_{t}\right)
$$

Exchange rates $(E R)$ are forward-looking and reflect an uncovered interest parity condition:

$$
E R_{t}=E R_{t+1}+\left(\frac{1+i_{t}^{*}}{1+i_{t}}\right)\left(1+R P_{t}\right)
$$

where $i_{t}^{*}$ is the short-term interest rate abroad.

Short-term interest rates are determined by monetary policy rules. The standard treatment is to target a combination of inflation and a nominal aggregate:

$$
i_{t}=v\left(\text { inf }_{t}-\text { inft }_{t}\right)+(1-v)\left(G D P N_{t}-G D P N T_{t}\right),
$$

where $\inf _{t}$ and inft $t_{t}$ are the actual and target inflation rate, and $G D P N_{t}$ and $G D P N T_{t}$ are actual and target nominal GDP. 


\section{The regional model}

UK-SCGE is a spatial computable general equilibrium model of the United Kingdom that we apply to determine how the NiGEM forecast is distributed across the UK. The model represents 109 regions of the UK - 86 in England, 9 in Scotland, 13 in Wales, and Northern Ireland - as separate economies linked by inter-regional trade flows. ${ }^{2}$ Figure 1 shows a geographic breakdown of the regions. The regions represent Housing Market Areas that reflect "...the optimal areas within which planning for housing should be carried out" (Jones et al, 2010). ${ }^{3}$

UK-SCGE is a dynamic model. The baseline simulation is designed to move the economy from an initial steady-state along a balanced growth path to a new steady-state. The policy simulation quantifies deviations of variables from their baseline values caused by the simulated policy change. The differences in the values of variables in the baseline and policy simulations quantify the effects of moving the variables of interest away from their baseline values.

UK-SCGE distinguishes 105 sectors and commodities based on the 2013 input-output (IO) tables published by ONS (2016). Primary factors are distinguished by 105 types of capital (one type per industry), 9 occupations and 2 types of land. The national IO table is disaggregated into regional IO tables using a combination of industry shares in employment or labour hours and commodity-specific consumption shares to split industries, investment, and government and private consumption across regions. This approach to deriving regional IO data is characterised as a hybrid method by Miller and Blair (2009). It most closely resembles the GRIT (Generation of Regional Input-Output Tables) technique; see, for example, West (1990).

A representative firm in each sector produces a single commodity. Some commodities produced for use in the domestic market are divided into a margin and nonmargin component. The margin component of a commodity is used to facilitate the movement and sale of both imported and domestic commodities within the UK, and of the exported commodities to the point of exportation; EU and non-EU export destinations are distinguished. Margin commodities include such activities as the various modes of transportation, and wholesale and retail trade. The non-margin component is used as a direct

\footnotetext{
2 The regions are listed in the appendix 1.

${ }^{3}$ In terms of the Nomenclature of Territorial Units for Statistics applied in all European Union countries, the regions contain slightly less detail than the 139 regions in the NUTS Level 3 classification (ONS, 2019).
} 
input into industry activity, investment and government or private consumption across all regions.

Production technology is represented by nested CES and CRESH functions (Hanoch, 1971) allowing a high degree of flexibility in the parameterisation of substitution and technology parameters. The supply of labour within each region is determined by a labourleisure trade-off that allows workers in each occupation to respond to changes in after-tax wage rates thus determining the hours of work they offer to the labour market. The overall supply of labour is normalised on working-age population, which typically moves with population. 
Figure 1. The 109 regions in UK-SCGE

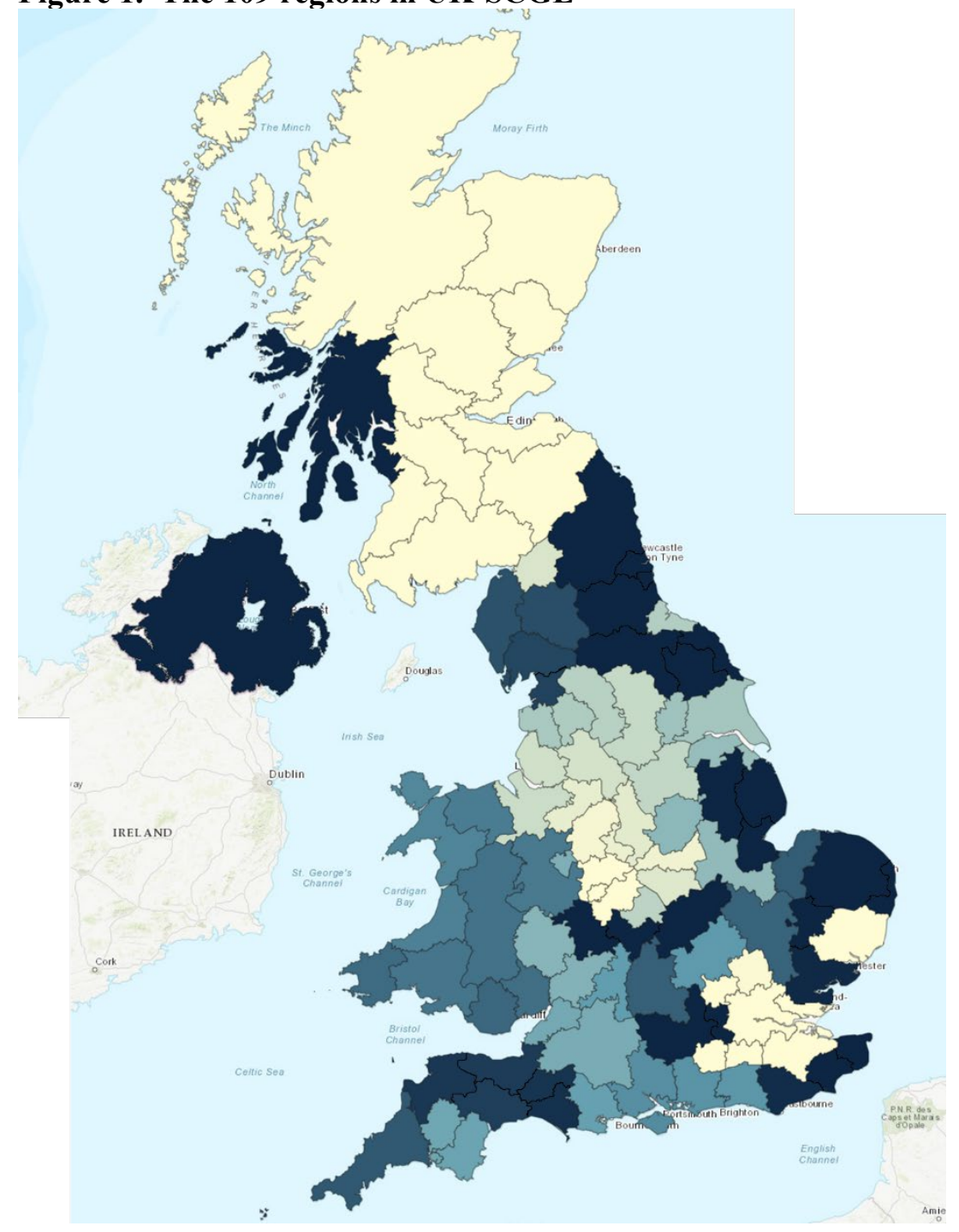

Household consumption decisions are determined by a Stone-Geary utility function (Stone, 1954) that distinguishes between subsistence (necessity) and discretionary (luxury) consumption.

UK-SCGE has detailed central and local government fiscal accounts, including the accumulation of public assets and liabilities. Government revenue is represented by direct and indirect taxes, and income from government enterprises. Government expenditure is represented by government consumption, investment and payments of various types of transfers (such as pensions and unemployment benefits).

Investment behaviour is industry specific and is positively related to the rate of return on capital. This rate incorporates into council taxes on housing and business rates on nondwellings. 
Foreign asset and liability accumulation is represented at the national level, as are the cross-border income flows they generate and that contribute to the evolution of the current account. Other foreign income flows such as labour payments and unrequited transfers are also represented giving a complete representation of primary and secondary income flows in the current account.

The following sections provide a formal presentation of those parts of the model important for understanding the analysis in the latter sections.

\subsection{Production technology}

Within each region, a representative firm in each sector produces a single commodity. ${ }^{4}$ Two broad categories of inputs are recognised: intermediate inputs and primary factors. Representative firms choose inputs of primary factors and intermediate inputs to minimise costs subject to a given production technology and given factor and commodity prices. Primary factors include two types of land, nine types of labour (occupations) ${ }^{5}$ and physical capital. Intermediate inputs potentially consist of 105 domestically-produced goods and services, each with a foreign substitute. ${ }^{6}$ Demands for primary factors and intermediate inputs are modelled using nested production functions. The nested production functions have three tiers.

At the top level, industry $i^{\text {'s }}$ activity $Q_{i}^{A C T}$ is determined as a Leontief combination of the intermediate input composite $Q_{\bullet_{i}}^{I N T}$ and the primary factor composite $Q_{\bullet_{i}}^{F A C}$ :

$$
Q_{i}^{A C T}=\min \left[\frac{Q_{\bullet i}^{I N T}}{A_{\bullet i}^{I N T}}, \frac{Q_{\bullet i}^{F A C}}{A_{\bullet i}^{F A C}}\right]
$$

where the $A$ variables represent unit input requirements.

At the second level of the production nest firms choose the optimal mix of the $c$ individual intermediate inputs $Q_{c i}^{I N T}$ using CRESH (constant ratios of elasticities of substitution, homothetic):

$$
\sum_{c}\left[\frac{Q_{c i}^{I N T}}{Q_{i}^{A C T} A_{c i}^{I N T}}\right]^{h_{c}} \frac{X_{c}}{h_{c}}=\alpha, \quad 0<h_{c}<1, X_{c}>0, \sum_{c} X_{c}=1, \alpha>0,
$$

\footnotetext{
${ }^{4}$ All the variables in this subsection have a region subscript but it has been dropped to reduce notational clutter, that is, the equations in this subsection are replicated in all regions of UK-SCGE.

5 The occupational classification corresponds to 1-digit occupations in ONS (2010).

${ }^{6}$ The actual number of intermediate inputs for each commodity will depend on the input data as represented in the IO tables.
} 
where $X_{c}, h_{c}$ and $\alpha$ are parameters and the $A$ variables represent unit input requirements. The CRESH formulation is due to Hanoch (1971) and it relaxes the assumption implied by CES functions that the elasticity of substitution between all pairs of inputs must be the same.

Thus, the elasticity of substitution between inputs $i$ and $j$ is $\sigma_{i} \sigma_{j} / \sum_{k=1}^{105} S_{k} \sigma_{k}$ where $\sigma_{i}=1 / 1-h_{i}$ is the CRESH parameter associated with input $i$ and $S_{k}$ is the k-th input's cost share. In the special case when all $\sigma_{i}$ have the same value, the CRESH system is equivalent to CES and all substitution elasticities are equal.

At the second level of the production nest firms also choose the optimal mix of the $f$ individual primary factors $Q_{f i}^{F A C}$ using CES production technology:

$$
Q_{\bullet i}^{F A C}=\left[\sum_{f} \chi_{f}\left(\frac{Q_{f i}^{F A C}}{A_{f i}^{F A C}}\right)^{-\rho}\right]^{-1 / \rho}, \quad 0<\chi_{f}<1, \sum_{f} \chi_{f}=1, \rho \geq-1, \rho \neq 0 .
$$

where $\chi_{f}$ and $\rho$ are parameters and the $A$ variables represent unit input requirements. The CES elasticity of substitution is $\sigma=1 /(1+\rho)$.

At the third level of the production nest, the composition of each commodity, land and labour are determined, by firms minimising costs subject to the constraints that:

(i) Each commodity is a CES composite of a domestic and imported variety;

(ii) Land is a CES composite of primary-production land and non-primary production land; and

(iii) Labour is a CES composite of nine skill types (that is, broad occupational categories).

\subsection{Zero-pure profits and market-clearing conditions}

Within each region, all firms are assumed to operate in competitive markets and thus take their output prices as given. Consistent with this, we impose a zero-pure-profits condition that equates revenues with costs and determines each industry's activity level or output:

$$
P_{i r} Q_{i r}^{A C T}=\sum_{c} P_{c i r}^{I N T} Q_{c i r}^{I N T}+\sum_{f} P_{f i r}^{F A C} Q_{f i r}^{F A C}
$$

In (15) the left-hand side is revenue for industry $i$ in region $r$; the right-hand side is the sum of intermediate input and primary factor costs for industry $i$ in region $r$.

Output prices of domestically-produced commodities are determined by a marketclearing condition that equates the quantity of each commodity supplied to a region with the 
total quantity of the commodity demanded by all users within the region. The same type of market-clearing condition applies to the imported varieties of each commodity by region of use. Note that imports are distinguished between those from EU and non-EU sources. The market-clearing condition is expressed as:

$$
Q_{c s d}^{U S E}=\sum_{u} Q_{c s u d}^{U S E}, s=\text { domestic, imported },
$$

where $Q_{c s u d}^{U S E}$ is the quantity of commodity $c$ from source $s$ used by user $u$ in region $d$ and $Q_{c s d}^{U S E}$ is the quantity of commodity $c$ from source $s$ supplied to region $d . Q_{c s d}^{U S E}$ is a CES composite, across all $r$ supplying regions, of $Q_{c s r d}^{D E L}$, the delivered supply of commodity $c$ from source $s$ produced or landed in region $r$ and delivered to region $d$.

There is also a market-clearing condition for margins that requires

$$
\sum_{p} Q_{m r d p}^{S U P M A R}=\sum_{c s} Q_{c s m r d}^{M A R}, s=\text { domestic, imported },
$$

where $Q_{m r d p}^{\text {SUPMAR }}$ is the supply of margin $m$ produced in region $p$ and used to facilitate the trade in goods and services from region $r$ to region $d$, and $Q_{c s m r d}^{M A R}$ is the quantity of margin $m$ used to facilitate the trade in commodity $c$ from source $s$ to destination $d$.

The treatment of interregional trade embodied in equations (16) and (17) builds on the innovative approach developed by Horridge (2011). The two matrices that calibrate these equations are constructed by disaggregating national IO data across regions using production shares and consumption shares at the most detailed regional level available and then grossed up to the 109 regions applied in the model database. ${ }^{7}$ Once the initial regional disaggregation is completed, a modified gravity formula is applied to determine trade across regions in a way that is consistent with a each region's implied excess demand by commodity. The trade totals and the gravity-formula-derived trade matrices are then reconciled using a matrix balancing algorithm (the RAS procedure).

\subsection{Primary factor supplies}

Two types of land are distinguished within each region: primary production and nonprimary production land. Primary production land is used only by the agricultural and mining industries. Non-primary production land consists of commercial land and residential land. Non-primary production land used by the dwellings sector represents residential land;

\footnotetext{
7 The method applies gross value added data from the Regional Accounts, industry employment data from the Business Register and Employment Survey, and population data by Local Authority Districts. All of these data are sourced from the Office for National Statistics website.
} 
non-primary production land used by all other sectors represents commercial land. In a baseline simulation (see section 5.2) land supply grows at the 30-year average GDP growth rate; in a policy simulation (see section 6) the supply of each type of land is fixed. For a given supply of the land type $l$, movements across the $i$ industries are governed by a CRETH (constant ratio of elasticities of transformation, homothetic) function due to Vincent et al (1980):

$$
\sum_{i}\left[\frac{Q_{l i}^{L N D}}{Q_{l}^{L N D} A_{l i}^{L N D}}\right]^{h_{i}} \frac{V_{i}}{h_{i}}=\beta, \quad h_{i}>1, V_{i}>0, \sum_{i} V_{i}=1, \beta>0,
$$

where $V_{i}, h_{i}$ and $\beta$ are parameters, and $Q_{l}^{L N D}$ is the supply of land type $l$ and $A$ represents unit input requirements. The CRETH functional form is identical to the CRESH form except for the restrictions on $m_{i}$; the CRESH form requires $0<h_{c}<1$ whereas the CRETH form requires $h_{i}>1$.

Nine labour types are distinguished in each region the supplies of which $Q_{n}^{L A B}(n=$ $1, \ldots, 9)$ are determined by an infinitely-lived representative household based on a labourleisure trade-off that allows workers in each occupation to respond to changes in real postincome-tax wage rates $R W_{n}$. This gives upward-sloping labour supply curves for industries and occupations:

$$
\frac{Q_{n}^{L A B}}{P O P}=\left(R W_{n}\right)^{\sigma} \Gamma_{n}
$$

where $\sigma$ is the uncompensated labour supply elasticity. There is a similarly defined labour supply function at the national level. At the national level the elasticity of labour supply is set at 0.15 reflecting econometric evidence for the UK (Bargain et al, 2011). At the regional level the labour supply elasticity is set at 0.5 to reflect limited interregional mobility of labour types. The divergent assumptions on regional and national labour supply responsiveness are reconciled by movements in $\Gamma_{n}$.

Each industry uses capital specific to its own production process. Thus, the supply of an industry's capital stock available for use in year $t$ is of similar form to NiGEM but is specified by industry. This representation of capital accumulation assumes that there is a one year gestation lag between investment by firms and an increment to the capital available for use by firms. 


\section{Regional growth prospects}

Here we describe the central macroeconomic scenario over the medium term. We then describe the regional outcomes conditional on this macroeconomic scenario.

\subsection{The macroeconomic scenario}

The macro scenario used for this analysis is the NIESR November 2018 central forecast discussed in Hantzsche et al. (2018). It is conditional on a 'soft' Brexit, broadly an assumption that the UK would trade on similar terms with the EU after Brexit as it had when it was an EU member. At the time this was a possible outcome and a useful assumption for forecasting purposes and scenario analysis. NIESR analysed other possible scenarios against the soft-Brexit benchmark in, for example, Hantzsche et al. (2019).

There is much uncertainty around this central scenario due partly to the unresolved nature of the future relationship between the UK and the EU. The short-term uncertainty is illustrated in Figure 2 by a fan-chart for UK GDP showing 'standard' macroeconomic risks. The fan is constructed so that there is an 80 per cent chance that future outcomes for GDP lie within the fan. Unusual risks, such as COVID-19, are ever-present and reflected in the 20 per cent chance that GDP lies outside of the fan.

\section{Figure 2. Fan chart for UK GDP}

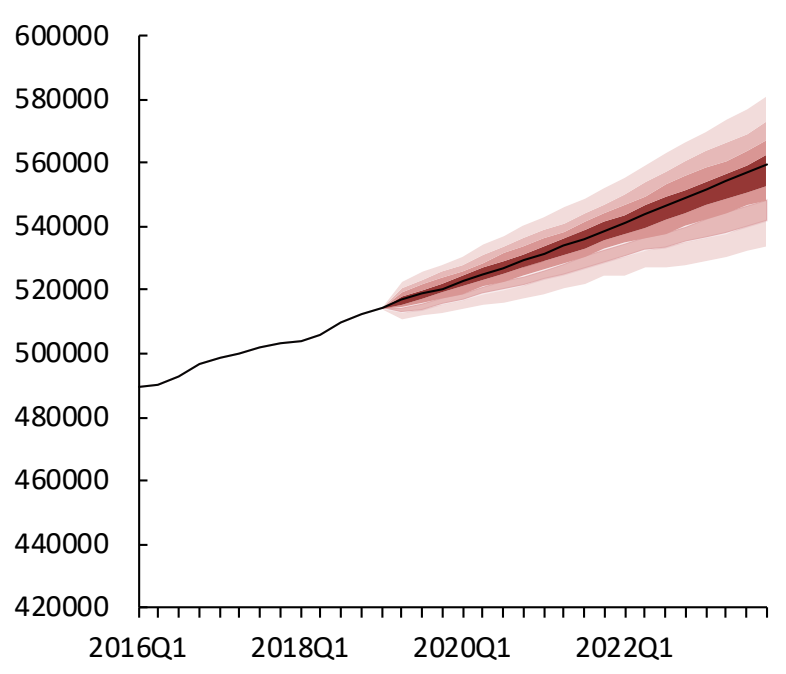

Note: Eighty per cent of future outcomes for GDP lie within the fan. These reflect 'standard' macroeconomic risks.

Under this central scenario the UK government is able to comply with the fiscal mandate but it is not able to achieve its medium-term objective to balance the budget unless it 
chooses to tax more. The details of the forecast appear in Table 1. Figures 3 and 4 present the time path of the forecast variables in the central scenario.

Table 1. Macro forecasts (average annual growth rates)

\begin{tabular}{lccc}
\hline \hline & $2021-2030$ & $2031-2040$ & $2040-44$ \\
\hline Household consumption & 1.66 & 2.02 & 2.08 \\
Investment & 1.79 & 1.23 & 1.68 \\
Government consumption & 2.22 & 1.89 & 1.90 \\
Exports & 1.83 & 1.12 & 1.89 \\
Imports & 1.58 & 2.31 & 2.19 \\
GDP & 1.86 & 1.51 & 1.89 \\
Capital & 2.07 & 1.68 & 1.58 \\
Labour hours & 0.39 & 0.36 & 0.43 \\
Labour productivity & 1.47 & 1.08 & 1.43 \\
Employment & 0.39 & 0.37 & 0.44 \\
Labour supply & 0.48 & 0.45 & 0.44 \\
Population & 0.46 & 0.33 & 0.29 \\
Real wage & 1.68 & 1.81 & 1.47 \\
GDP deflator & 2.03 & 2.35 & 2.09 \\
CPI & 1.97 & 1.82 & 1.97 \\
Export price index & 2.16 & 2.08 & 2.07 \\
Import price index & 2.35 & 0.64 & 1.64 \\
PSBR (\% of GDP) & -0.026 & -0.020 & -0.017 \\
Current account (\% of GDP) & -0.019 & -0.025 & -0.019 \\
\hline \hline
\end{tabular}

Note: All figures are percentage changes unless otherwise stated. PSBR $=$ Public Sector Borrowing Requirement.

Figure 3. GDP expenditure components

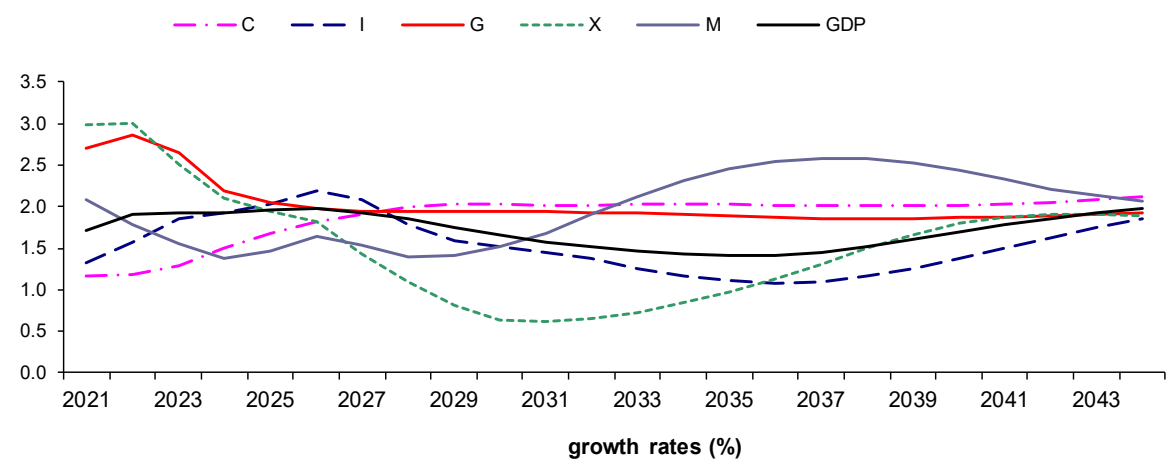

Figure 4. GDP income components

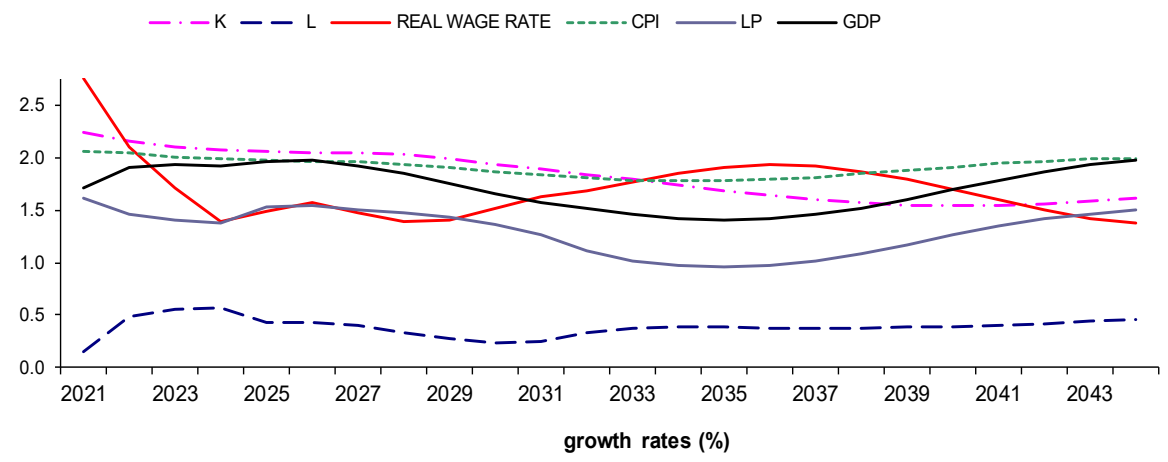


The fiscal central scenario faces a number of other risks. If population ageing was faster than is currently expected, spending requirements would be higher. External shocks due to global trade tensions would affect spending requirements and the revenue base, and may increase borrowing costs if risk premia rose. Higher than forecast productivity growth would improve the long-term fiscal outlook.

The assumptions on the path of economywide productivity growth are independent of Brexit. The central scenario reflects 10 years of low productivity performance and hourly productivity growth is assumed to be just under $1.5 \%$ per annum. Labour productivity continues to recover very gradually some of the losses made since the financial crisis but given the lack of clarity about future trading relationships with the EU, the outlook remains uncertain in the short- and medium-term. The annual growth rate of output per hour is forecast to stabilise at around $1.5 \%$ in the medium term.

The central scenario assumes that the UK population grows according to principal projections provided by the Office for National Statistics. These imply a fall in net migration to around 200,000 people per year in the medium term.

The central scenario assumes that the household saving rate will begin to rise over the medium term towards its long-run average and that the corporate saving to GDP ratio remains around $9 \%$ in the medium term. Corporate investment remains at about $10 \%$ of GDP in the medium term.

\subsection{The regional picture}

Applying the macro forecast to UK-SCGE allows us to generate long-run results for the 109 regions as presented in table 2, column 5. ${ }^{8}$ Aggregating these results to the four countries indicates the degree of divergence across broad parts of the UK. Figure 4 shows that country output growth diverges little across the forecast horizon. The only noticeable feature is that Scotland grows noticeably faster over the periods 2020-2024 and 2033-2041. In terms of average annual growth, Scotland leads with $1.78 \%$, followed England and Northern Ireland at $1.71 \%$ and 1.72 , and then Wales at $1.70 \%$. These growth rates translate into cumulative changes of $55.7 \%$ (England), 55.2\% (Wales), 58.4\% (Scotland) and 56.10\% (Northern Ireland) over the forecast period.

There are four major drivers of GDP growth in the NiGEM forecast: labour productivity, housing investment, business investment and export prices. Figure 5 presents

\footnotetext{
${ }^{8}$ See appendix 2 for a description of how the NiGEM forecasts are applied to UK-SCGE.
} 
the GDP outcomes when we apply each of these drivers individually. This gives an indication of the importance of each driver to the overall GDP outcome. Labour productivity is the most important driver of GDP growth over the forecast horizon. The other drivers are much less important; of these, housing investment and export prices are the most important. Business investment makes the smallest contribution of the four drivers, and in the second half of the horizon makes almost no contribution to GDP.

The weak contribution of business investment to GDP growth reflects the slow growth in business investment relative to GDP growth over the forecast horizon: see figure 3. Business investment averages 1.43\% growth compared with $1.71 \%$ for GDP. By contrast, housing investment is the second most important contributor to GDP growth: it averages $2.52 \%$. Growth in total investment (business, private and government) averages $1.62 \%$ over the forecast horizon. The weak contribution of business investment to GDP growth reflects the longer run effects of Brexit where risk premia are expected to be higher than otherwise.

Relative export prices make a strong positive contribution over the first and last third of the forecast horizon. These movements reflect movements in the exchange rate and import prices in export destinations. Initially, higher export prices reflect the expected depreciation of the exchange rate due to the uncertainties related to Brexit. The depreciation dissipates by 2025, after which the movements in export prices mainly reflect price movements in export destinations. 
Figure 5. Country GDP

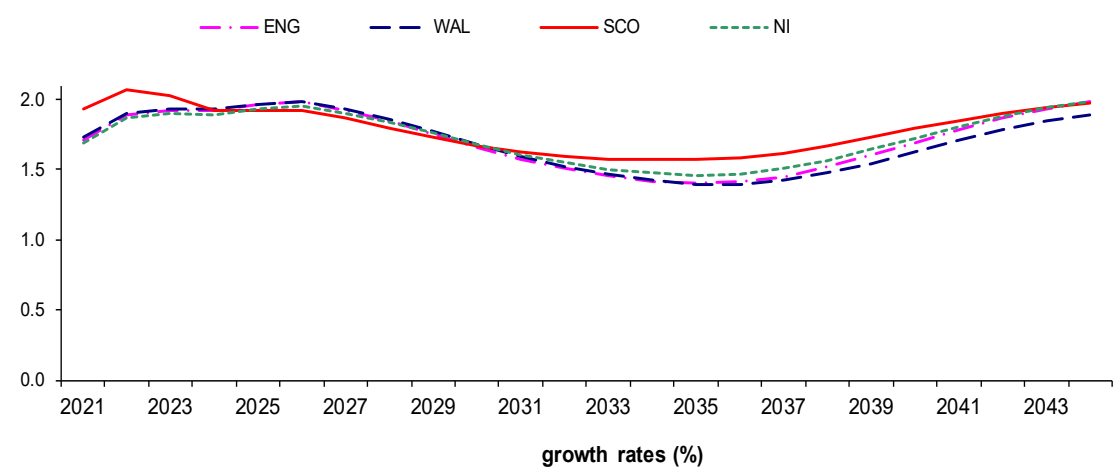

Figure 6. Decomposition of GDP

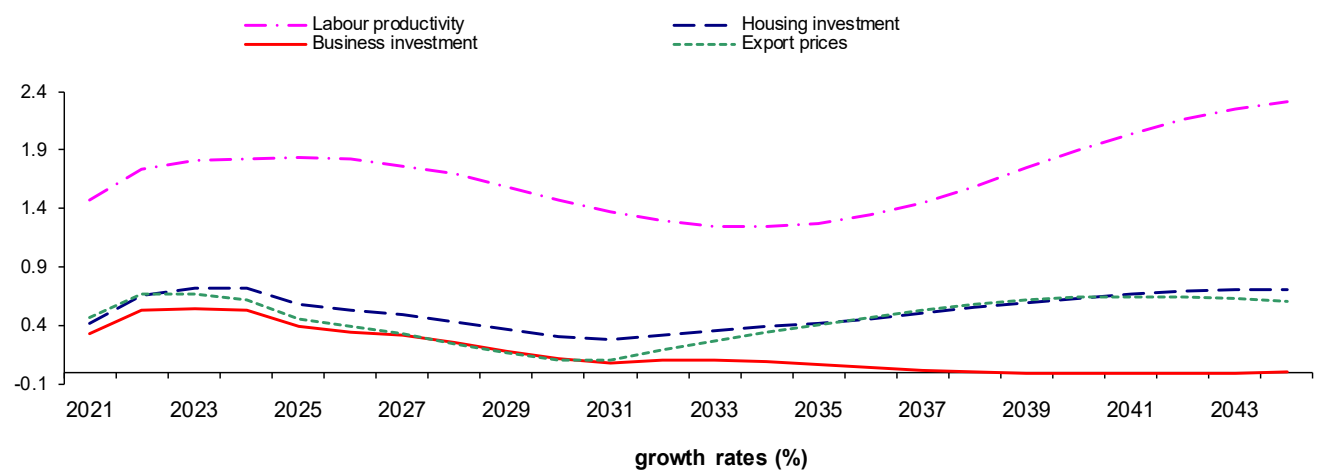

\subsection{The fastest and slowest growing regions}

In a model with a 109 regions there is a major challenge to understand what determines the differences in growth rates across regions. Inspection of table 2 reveals that the fastest growing region is Pembrokeshire (south-west Wales) with average growth of $2.17 \%$ and the slowest growing region is Cambridge (east England) with average growth of $1.64 \%$. We can present a decomposition of the four major drivers of GDP growth (similar to figure 6) for all regions. This is done in figure 7. Due to the clustering of growth rates it is difficult to discern strong patterns in figure 7. One discernible pattern is that labour productivity is the largest contributor to GDP growth for all regions; other patterns are less clear.

To aid in revealing more patterns requires that the results are filtered to some extent. In figure 8 we present the results for the five fastest and five slowest growing regions. The five fastest growing regions are Pembrokeshire (south-west Wales) 2.17\%, North Lincolnshire (east England) 2.11\%, Allerdale (north-west England) 1.91\%, Cheshire West (north-west England) 1.90\%, North East Lincolnshire (east England) 1.86\%. The five fastest slowing regions are Boston (east England) 1.67\%, East Dunbartonshire (west central 
Scotland) 1.66\%, Guildford (south England) 1.66\%, Barrow-in-Furness (north-west England) $1.66 \%$, and Cambridge (east England) 1.64\%. 
Table 2. Regional GDP outcomes: decomposition (average annual growth rates)

\begin{tabular}{|c|c|c|c|c|c|}
\hline & $\begin{array}{c}(1) \\
\text { Labour } \\
\text { productivity }\end{array}$ & $\begin{array}{c}(2) \\
\text { Housing } \\
\text { investment }\end{array}$ & $\begin{array}{c}(3) \\
\text { Business } \\
\text { investment }\end{array}$ & $\begin{array}{c}(4) \\
\text { Export } \\
\text { price }\end{array}$ & $\begin{array}{c}(5) \\
\text { Total }\end{array}$ \\
\hline$\overline{\text { National }}$ & 1.66 & 0.53 & 0.20 & 0.47 & 1.72 \\
\hline 1. Dudley & 1.59 & 0.57 & 0.31 & 0.52 & 1.76 \\
\hline 2. Birmingham & 1.64 & 0.51 & 0.18 & 0.44 & 1.73 \\
\hline 3. Cannock Chase & 1.63 & 0.61 & 0.30 & 0.55 & 1.77 \\
\hline 4. Babergh & 1.69 & 0.32 & 0.20 & 0.42 & 1.75 \\
\hline 5. Aberdeen & 2.12 & 1.05 & 0.68 & 1.12 & 1.80 \\
\hline 6. Scottish Borders & 1.61 & 0.51 & 0.18 & 0.41 & 1.68 \\
\hline 7. Dumfries Galloway & 1.62 & 0.44 & 0.25 & 0.43 & 1.69 \\
\hline 8. Angus & 1.62 & 0.48 & 0.17 & 0.43 & 1.68 \\
\hline 9. Fife & 1.66 & 0.46 & 0.20 & 0.45 & 1.68 \\
\hline 10. Eilean Siar & 1.70 & 0.60 & 0.21 & 0.52 & 1.68 \\
\hline 11. Perth \& Kinross & 1.63 & 0.53 & 0.15 & 0.43 & 1.68 \\
\hline 12. Clackmannanshire & 1.84 & 0.67 & 0.30 & 0.63 & 1.73 \\
\hline 13. East Lothian & 1.76 & 0.50 & 0.14 & 0.48 & 1.69 \\
\hline 14. East Dunbartonshire & 1.64 & 0.50 & 0.10 & 0.41 & 1.66 \\
\hline 15. East Ayrshire & 1.60 & 0.49 & 0.25 & 0.43 & 1.68 \\
\hline 16. London & 1.68 & 0.50 & 0.08 & 0.34 & 1.69 \\
\hline 17. Southend-on-Sea & 1.60 & 0.50 & 0.12 & 0.38 & 1.72 \\
\hline 18. Medway & 1.65 & 0.60 & 0.19 & 0.47 & 1.74 \\
\hline 19. Mole Valley & 1.80 & 0.53 & 0.12 & 0.46 & 1.69 \\
\hline 20. Guildford & 1.67 & 0.35 & -0.04 & 0.30 & 1.66 \\
\hline 21. Dacorum & 1.66 & 0.47 & 0.02 & 0.35 & 1.70 \\
\hline 22. East Hertfordshire & 1.65 & 0.52 & 0.13 & 0.43 & 1.72 \\
\hline 23. Stoke-on-Trent & 1.58 & 0.59 & 0.30 & 0.55 & 1.78 \\
\hline 24. Charnwood & 1.67 & 0.45 & 0.19 & 0.45 & 1.70 \\
\hline 25. East Staffordshire & 1.56 & 0.65 & 0.28 & 0.48 & 1.75 \\
\hline 26. Cheshire East & 1.74 & 0.40 & 0.10 & 0.42 & 1.71 \\
\hline 27. Derby & 1.64 & 0.49 & 0.22 & 0.47 & 1.74 \\
\hline 28. Leicester & 1.62 & 0.52 & 0.21 & 0.44 & 1.71 \\
\hline 29. Carlisle & 1.59 & 0.66 & 0.30 & 0.51 & 1.75 \\
\hline 30. Manchester & 1.65 & 0.53 & 0.21 & 0.47 & 1.71 \\
\hline 31. Halton & 1.64 & 0.53 & 0.24 & 0.50 & 1.75 \\
\hline 32. Cheshire West and Chester & 1.64 & 0.48 & 0.28 & 0.68 & 1.90 \\
\hline 33. Barnsley & 1.62 & 0.51 & 0.20 & 0.44 & 1.70 \\
\hline 34. Doncaster & 1.59 & 0.54 & 0.26 & 0.49 & 1.71 \\
\hline 35. Coventry & 1.64 & 0.47 & 0.17 & 0.46 & 1.74 \\
\hline 36. Bradford & 1.66 & 0.55 & 0.29 & 0.50 & 1.74 \\
\hline 37. Hartlepool & 1.68 & 0.69 & 0.37 & 0.67 & 1.82 \\
\hline 38. Blackburn with Darwen & 1.65 & 0.49 & 0.29 & 0.50 & 1.73 \\
\hline 39. Blackpool & 1.63 & 0.59 & 0.29 & 0.55 & 1.75 \\
\hline 40. East Riding of Yorshire & 1.63 & 0.60 & 0.32 & 0.55 & 1.76 \\
\hline 41. York & 1.61 & 0.54 & 0.21 & 0.46 & 1.68 \\
\hline 42. North East Lincolnshire & 1.71 & 0.38 & 0.31 & 0.57 & 1.89 \\
\hline 43. North Lincolnshire & 1.59 & 0.40 & 0.26 & 0.89 & 2.11 \\
\hline 44. Rutland & 1.64 & 0.49 & 0.21 & 0.44 & 1.68 \\
\hline 45. Nottingham & 1.58 & 0.50 & 0.21 & 0.44 & 1.70 \\
\hline 46. Herefordshire & 1.60 & 0.61 & 0.27 & 0.50 & 1.75 \\
\hline 47. Cheltenham & 1.67 & 0.48 & 0.17 & 0.45 & 1.72 \\
\hline 48. Telford and Wrekin & 1.68 & 0.56 & 0.26 & 0.53 & 1.75 \\
\hline 49. Bath and North East Somerset & 1.63 & 0.54 & 0.17 & 0.45 & 1.73 \\
\hline 50. Bristol & 1.69 & 0.52 & 0.14 & 0.44 & 1.70 \\
\hline 51. Plymouth & 1.55 & 0.51 & 0.26 & 0.45 & 1.69 \\
\hline 52. Torbay & 1.54 & 0.62 & 0.28 & 0.50 & 1.71 \\
\hline 53. Bournemouth & 1.63 & 0.55 & 0.21 & 0.44 & 1.72 \\
\hline 54. Swindon & 1.73 & 0.52 & 0.17 & 0.48 & 1.72 \\
\hline 55. Bedford & 1.66 & 0.43 & 0.11 & 0.40 & 1.70 \\
\hline
\end{tabular}


Table 2. Regional GDP outcomes: decomposition (average annual growth rates) (cont)

\begin{tabular}{|c|c|c|c|c|c|}
\hline & $\begin{array}{c}(1) \\
\text { Labour } \\
\text { productivity }\end{array}$ & $\begin{array}{c}\text { (2) } \\
\text { Housing } \\
\text { investment }\end{array}$ & $\begin{array}{c}\text { (3) } \\
\text { Business } \\
\text { investment }\end{array}$ & $\begin{array}{l}\text { (4) } \\
\text { Export } \\
\text { price }\end{array}$ & $\begin{array}{c}(5) \\
\text { Total }\end{array}$ \\
\hline Brighton and Hove & 1.71 & 0.54 & 0.17 & 0.47 & 1.73 \\
\hline Portsmouth & 1.63 & 0.49 & 0.17 & 0.42 & 1.72 \\
\hline Southampton & 1.68 & 0.39 & 0.09 & 0.41 & 1.73 \\
\hline Isle of Wight & 1.56 & 0.47 & 0.21 & 0.40 & 1.73 \\
\hline Isle of Anglesey & 1.77 & 0.38 & 0.41 & 0.56 & 1.80 \\
\hline Gwynedd & 1.65 & 0.99 & 0.77 & 0.93 & 1.75 \\
\hline Ceredigion & 1.66 & 0.90 & 0.69 & 0.86 & 1.74 \\
\hline Conwy & 1.63 & 1.01 & 0.79 & 0.95 & 1.76 \\
\hline Shropshire & 1.58 & 0.70 & 0.29 & 0.56 & 1.78 \\
\hline Carmarthenshire & 1.69 & 0.86 & 0.67 & 0.85 & 1.77 \\
\hline Powys & 1.67 & 0.87 & 0.68 & 0.84 & 1.75 \\
\hline 67. Blaenau Gwent & 1.73 & 0.80 & 0.60 & 0.79 & 1.76 \\
\hline 68. Pembrokeshire & 1.66 & 0.51 & 0.44 & 0.99 & 2.17 \\
\hline 69. Bridgend & 1.76 & 0.80 & 0.60 & 0.80 & 1.75 \\
\hline 70. Cambridgeshire & 1.62 & 0.35 & 0.03 & 0.31 & 1.64 \\
\hline 71. Cherwell & 1.66 & 0.43 & 0.01 & 0.36 & 1.68 \\
\hline 72. King's Lynn and West Norfolk & 1.55 & 0.65 & 0.30 & 0.48 & 1.75 \\
\hline 73. Cornwall & 1.53 & 0.63 & 0.32 & 0.51 & 1.71 \\
\hline 74. Isles of Scilly & 1.62 & 0.64 & 0.23 & 0.50 & 1.86 \\
\hline 75. Allerdale & 1.65 & 0.53 & 0.30 & 0.72 & 1.91 \\
\hline 76. Eden & 1.63 & 0.56 & 0.34 & 0.53 & 1.69 \\
\hline 77. Barrow-in-Furness & 1.62 & 0.30 & 0.23 & 0.36 & 1.66 \\
\hline 78. South Lakeland & 1.65 & 0.57 & 0.29 & 0.51 & 1.71 \\
\hline 79. Lancaster & 1.70 & 0.68 & 0.41 & 0.68 & 1.73 \\
\hline 80. East Devon & 1.57 & 0.65 & 0.22 & 0.48 & 1.73 \\
\hline 81. Sedgemoor & 1.57 & 0.54 & 0.26 & 0.46 & 1.68 \\
\hline 82. North Devon & 1.64 & 0.58 & 0.26 & 0.50 & 1.72 \\
\hline 83. South Somerset & 1.63 & 0.49 & 0.23 & 0.46 & 1.73 \\
\hline 84. West Dorset & 1.56 & 0.57 & 0.25 & 0.46 & 1.70 \\
\hline 85. Eastbourne & 1.56 & 0.53 & 0.18 & 0.40 & 1.72 \\
\hline 86. Braintree & 1.62 & 0.59 & 0.21 & 0.47 & 1.75 \\
\hline 87. Malvern Hills & 1.61 & 0.63 & 0.22 & 0.49 & 1.77 \\
\hline 88. Ashford & 1.57 & 0.48 & 0.18 & 0.40 & 1.69 \\
\hline 89. Canterbury & 1.63 & 0.32 & 0.20 & 0.42 & 1.76 \\
\hline 90. Lincoln & 1.61 & 0.55 & 0.28 & 0.50 & 1.71 \\
\hline 91. Boston & 1.59 & 0.46 & 0.30 & 0.45 & 1.67 \\
\hline 92. East Lindsey & 1.52 & 0.53 & 0.36 & 0.51 & 1.69 \\
\hline 93. Breckland & 1.66 & 0.51 & 0.23 & 0.46 & 1.69 \\
\hline 94. Forest Heath & 1.65 & 0.50 & 0.17 & 0.45 & 1.70 \\
\hline 95. Great Yarmouth & 1.63 & 0.47 & 0.26 & 0.46 & 1.68 \\
\hline 96. Corby & 1.61 & 0.50 & 0.20 & 0.44 & 1.72 \\
\hline 97. Hambleton & 1.65 & 0.60 & 0.30 & 0.54 & 1.71 \\
\hline 98. Ryedale & 1.69 & 0.51 & 0.18 & 0.48 & 1.72 \\
\hline 99. Scarborough & 1.58 & 0.63 & 0.39 & 0.58 & 1.72 \\
\hline 100. Argyll \& Bute & 1.68 & 0.58 & 0.20 & 0.50 & 1.71 \\
\hline 101. County Durham & 1.61 & 0.65 & 0.38 & 0.59 & 1.77 \\
\hline 102. Gateshead & 1.62 & 0.54 & 0.24 & 0.49 & 1.73 \\
\hline 103. Inverclyde & 1.63 & 0.53 & 0.21 & 0.46 & 1.73 \\
\hline 104. Hillingdon & 1.67 & 0.40 & 0.07 & 0.38 & 1.70 \\
\hline 105. Stratford-on-Avon & 1.73 & 0.59 & 0.22 & 0.60 & 1.85 \\
\hline 106. Sunderland & 1.69 & 0.61 & 0.34 & 0.61 & 1.81 \\
\hline 107. Bracknell Forest & 1.71 & 0.40 & 0.02 & 0.39 & 1.69 \\
\hline 108. Northumberland & 1.59 & 0.69 & 0.41 & 0.60 & 1.75 \\
\hline 109. Northern Ireland & 1.65 & 0.54 & 0.27 & 0.52 & 1.73 \\
\hline
\end{tabular}




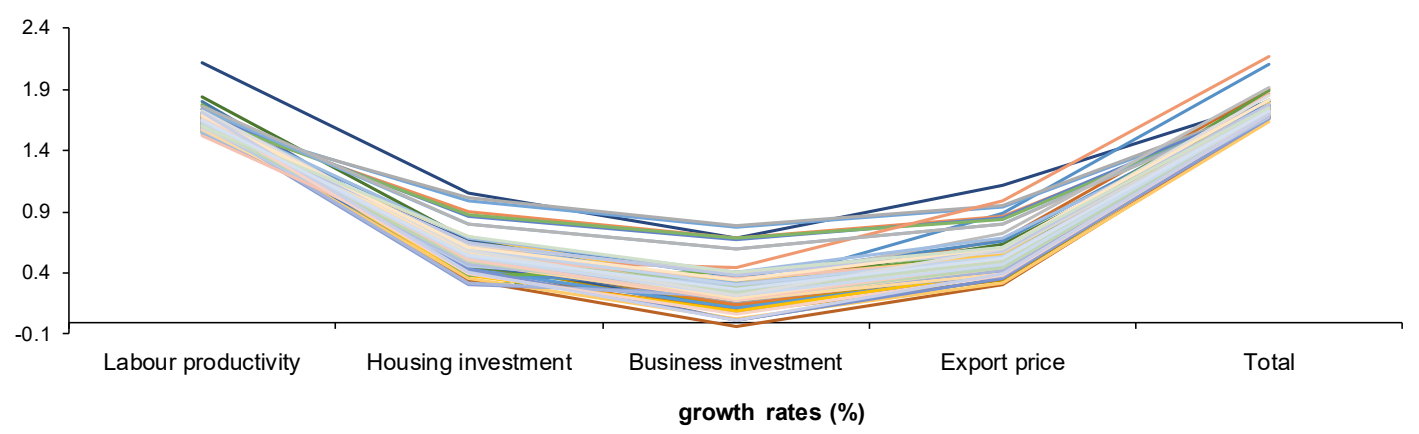

Figure 8. Decomposition of GDP: 5 fastest and 5 slowest growing regions

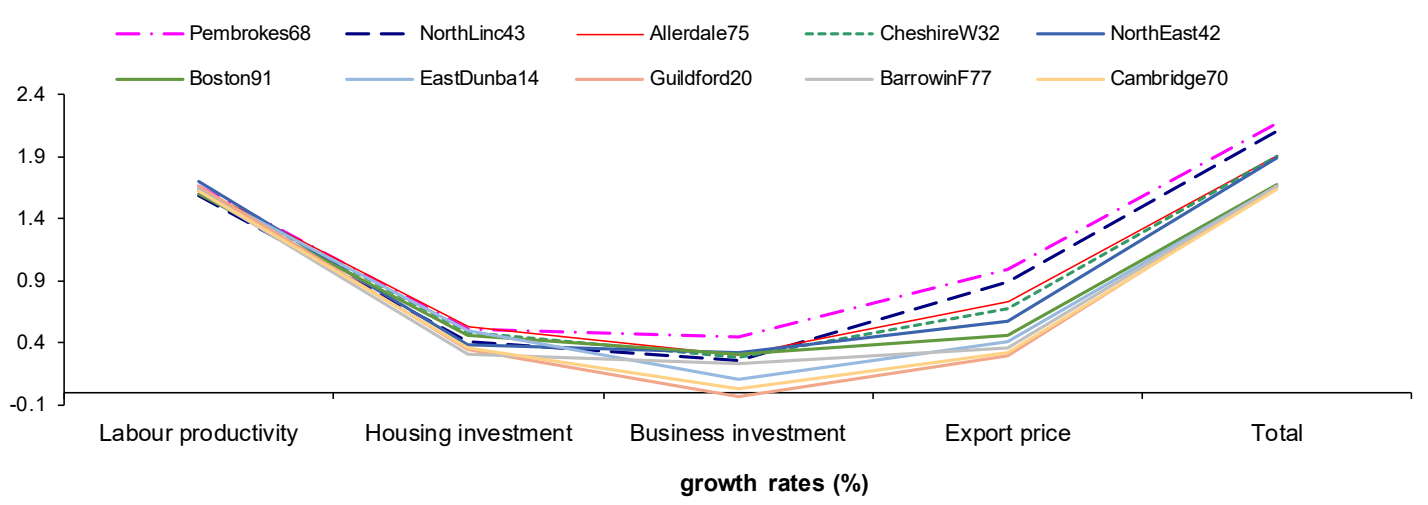

Figure 8 confirms that although the average growth rate between five fastest and five slowest growing regions varies from $2.17 \%$ to $1.64 \%$, labour productivity makes an almost identical contribution to GDP growth for each of these regions. While housing investment is a much less important contributor than labour productivity, nevertheless its contribution is also very even across these 10 regions. The largest variation in GDP contributions is seen for business investment and export prices.

The contribution of export prices reflects the importance of international trade in each regional economy. Pembrokeshire, North East Lincolnshire and North Lincolnshire have very high trade shares in GDP (ranging from 70\% to 370\%). Exports and output in these regions are dominated by manufactures: some of the most important manufactures are oil refining in Pembrokeshire and North Lincolnshire, and basic chemicals, fertilisers and plastics in North East Lincolnshire. The importance of these industries in each of these regions means there are large output multipliers from international exports of these products. In contrast, Guildford, Barrow-in-Furness and Cambridge have much lower trade shares (ranging from $7 \%$ to 30\%). Thus, Pembrokeshire, North East Lincolnshire and North 
Lincolnshire benefit strongly from higher export prices whereas Guildford, Barrow-inFurness and Cambridge do not.

Housing investment makes a similar contribution to GDP for the five fastest and five slowest growing regions. By contrast, the contribution of business investment varies significantly between these two groups of regions. Nationally, housing and business investment comprise $3 \%$ and $17 \%$ of GDP. All other things being equal, a given growth rate in housing investment will be much less important in determining output growth for a region than a given growth rate in business investment. Thus, we observe that variations in the importance of business investment in a region reflect differences in growth rates across these two groups of regions. That is, the fastest growing regions have business investment shares less than average and the slowest growing regions have business investment shares above average.

\section{A government expenditure shock}

Having generated long-run results for the 109 regions we now impose a deviation around this baseline to demonstrate the policy behaviour of the regional model. We impose a permanent $10 \%$ increase in central and local government consumption expenditure in all regions over 2019-2020. The increased government consumption is initially financed by government borrowing thus allowing the government budget to deteriorate. From 2021 onwards the income tax rate slowly rises to restore the government budget as share of GDP to baseline levels. Note that the current account as a share of GDP is held at baseline levels via an endogenous household saving rate.

\subsection{National effects}

During the expansion in government consumption the budget balance deteriorates by 2.5 percentage points of GDP (figure 9). From 2021 the income tax rate rises at a decreasing rate until the baseline budget-to-GDP ratio is approximately restored in 2034 . The macroeconomic effects of these changes are shown in figures 10 and 11 . In imposing the increase in government consumption over 2019-20 we apply a modified version of the NIGEM wage equation for the UK:

$$
\ln W_{t}=\ln W_{t-1}+v \text { labhrs }_{t}+\ln \left(C P I_{t} / C P I_{t-1}\right)-\psi U N R_{t-1},
$$


Figure 9. Budget balance and income tax rate

- - BBAL/GDP $\quad-\quad-$ INCOME TAXRATE

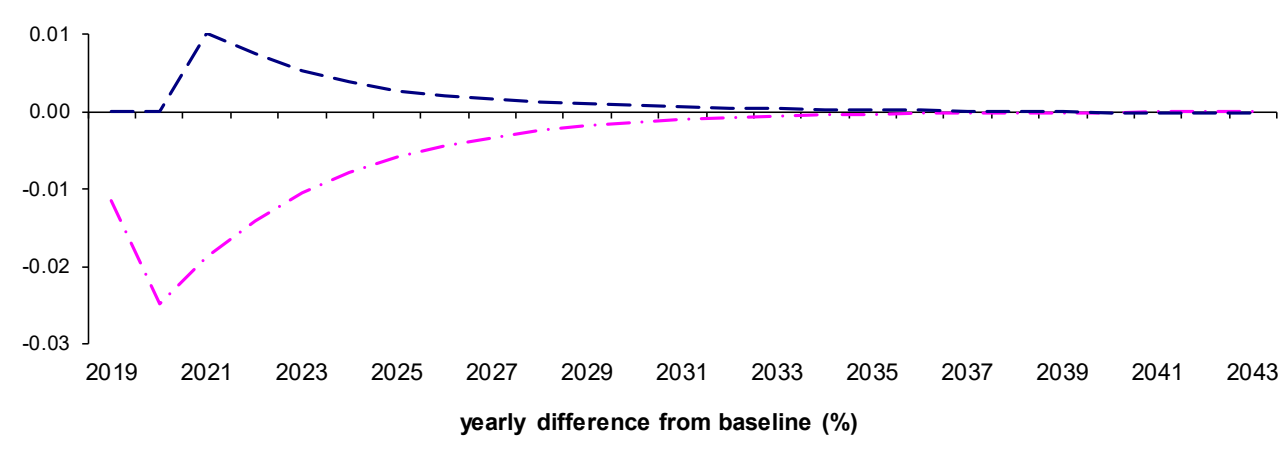

Figure 10. GDP income components

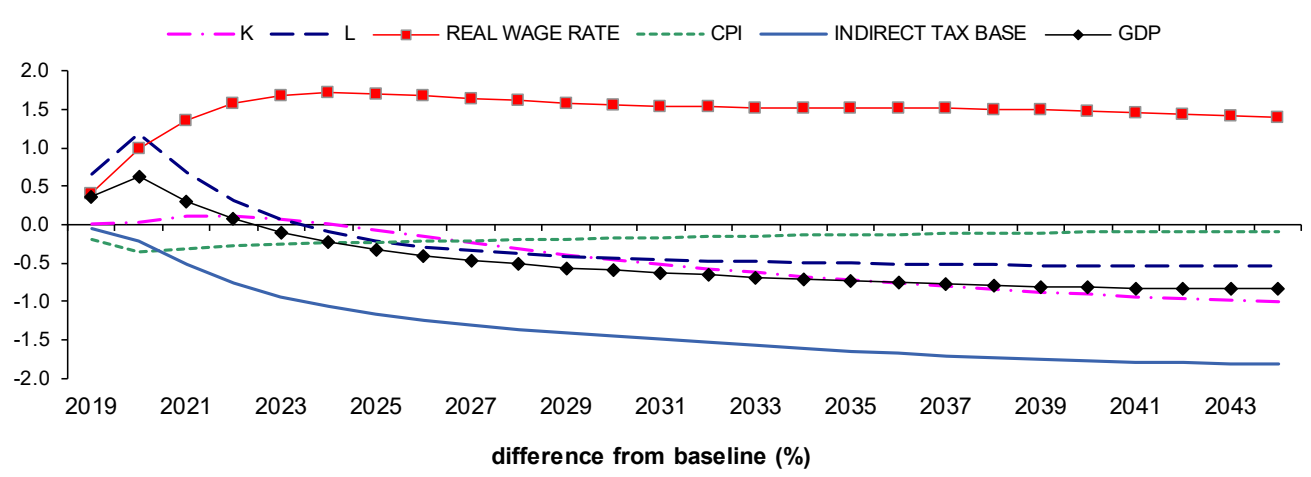

Figure 11. GDP expenditure components

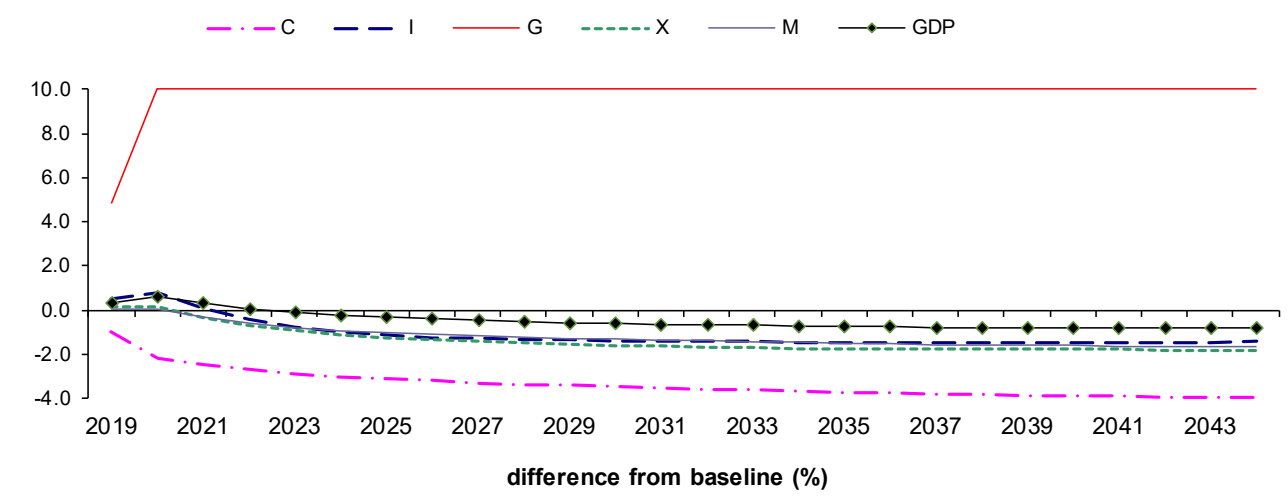

where $W$ is the wage rate, labhrs is labour hours, CPI is the consumer price index and UNR the unemployment rate. $v$ and $\psi$ are NIGEM parameters multiplied by four to approximate annual dynamics.

In the standard model treatment occupational wage rates are determined by market clearing by assuming fixed occupational unemployment rates. In contrast, equation (20) allows the aggregate wage rate to rise more slowly in response to the increase in government 
consumption compared to standard model treatment. We expect the aggregate wage rate to rise as government consumption is dominated by three labour-intensive services: health, education and public administration. A 10\% increase in demand for these services in the presence of inelastic labour supply (see equation (19)) will drive up wage rates for all sectors. Figure 10 shows that while the aggregate real wage rate rises over 2019-2020 it does so slowly enough that labour hours also rise. This translates into a fall in the unemployment rate of 1.5 percentage points by 2020 .

From 2021 onwards wage rates adjust so that the unemployment rate slowly returns to return to baseline levels by around 2026. Thus, labour hours eventually move $0.5 \%$ below baseline (figure 10). Employment settles at $0.24 \%$ above baseline reflecting a higher real wage and therefore labour supply. The capital stock is $1 \%$ lower by 2044 reflecting a fall in the capital-labour ratio. This is consistent with the expansion in government-provided services that are labour intensive and a contraction in other industries. Thus GDP is $0.84 \%$ lower by 2044 compared to baseline.

A smaller capital stock and reduced labours hours make a negative contribution to GDP but they do not fall enough to explain the fall in GDP. A further negative effect arises from the significant reduction in allocative efficiency, i.e., the indirect tax base (figure 10). The indirect tax base reflects the quantity base upon which indirect taxes are applied. ${ }^{9}$ As taxes (subsidies) reduce (increase) output and sales below (above) their optimal (undistorted) level, a decrease in the overall indirect tax base reflects a movement away from the optimal level of output. This occurs because the expanding industries (health, education and public administration) are lightly-taxed relative to industries as a whole. This means that an expansion in government-dominated industries relative to other industries reduces the indirect tax base and thus allocative efficiency. By 2044 the indirect tax base is $1.8 \%$ below baseline.

\subsection{Regional effects}

Figure 12 presents the regional GDP effects from lowest to highest. These range from $-1.54 \%$ in London to $2.67 \%$ in Conwyn. What explains this range of results? The nature of the shock we are assessing is generic across regions: a $10 \%$ increase in government consumption. What is not region-generic is the importance of government consumption in regional economic activity. Thus, it is probable that the main driver of regional GDP is the

\footnotetext{
${ }^{9}$ In simplified form the indirect tax base is $t X$ where $t$ is the tax rate and $X$ is the quantity demanded. $t X$ is related to the excess burden of a tax. For linear supply and demand curves the excess burden $\approx-1 / 2 t X$ (see Auerbach (1982)).
} 
share of government consumption in regional GDP. To test this idea we regress the percentage change in regional GDP $\left(\% \Delta G D P_{r}\right)$ on the share of government consumption in regional GDP $\left(G_{r} / G D P_{r}\right)$. This gives us the equation $\% \Delta G D P_{r}=-2.2495+9.0715\left(G_{r} / G D P_{r}\right)$ with an $\mathrm{R}^{2}$ of 0.88 . Thus the importance of government consumption in regional economic activity explains most of the GDP response by region. The regional GDP results and the fitted line are presented in figure 12 . The regression under- and over-predicts regional GDP with no discernible pattern. It seemed likely that adding variables reflecting the importance of international and domestic exports to the regression might further raise the explanatory power of the regression; these variables did so only marginally.

Figure 13 presents the effects on regional GDP and the expenditure components. The results show the crowding out effects of the increase in government consumption. Household consumption as a share of GDP noticeably contracts in all regions. This is to be expected as the increase in government consumption is eventually financed by a higher income tax, which reduces household disposable income and thus consumption. Investment is also crowded out but much less so as the company tax rate is unchanged. Nevertheless, as labour can migrate across regions it is drawn into the expanding regions. This partly ameliorates the crowding out effect on household consumption in the expanding regions.

International exports are strongly negatively affected in most regions. This reflects the increase in domestic prices relative to international prices, which makes international exports less competitive. Domestic prices are driven upwards by the higher real wage costs that are a result of the expansion in labour-intensive government-dominated industries. Domestic or regional exports are also negatively affected in most regions but much less so than international exports; this is because wage costs rise in all regions and so the relative price effects across regions are much smaller than the increase in domestic prices relative to international prices.

The crowding out effects on domestic and regional exports are most notable in those regions that experience the largest increases in GDP (Isle of Anglesey, Gwynedd, Ceredigion, Conwy, Carmarthenshire, Powys, Blaenau Gwent, Pembrokeshire and Bridgend). These are also the regions with the highest shares of government consumption in GDP. 
Figure 12. Regional GDP effects versus fitted regression (\%)

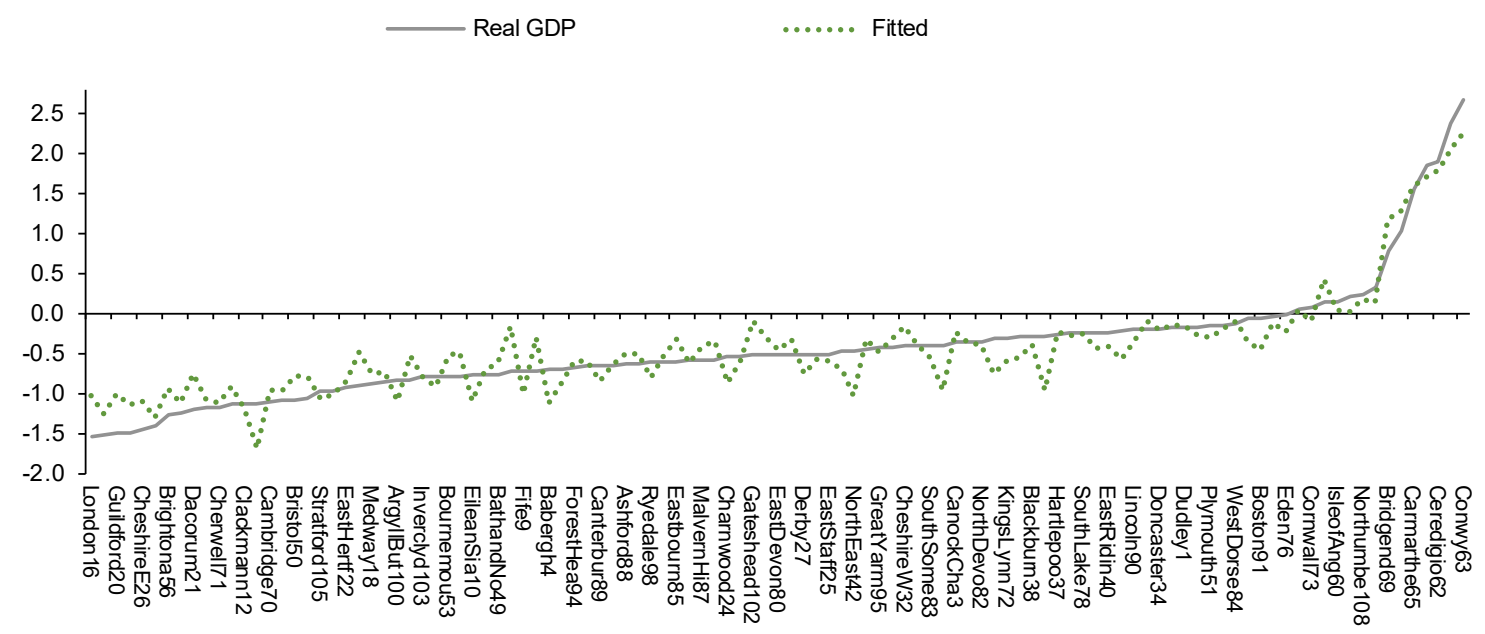

Figure 13. Regional GDP effects and expenditure components (\%)

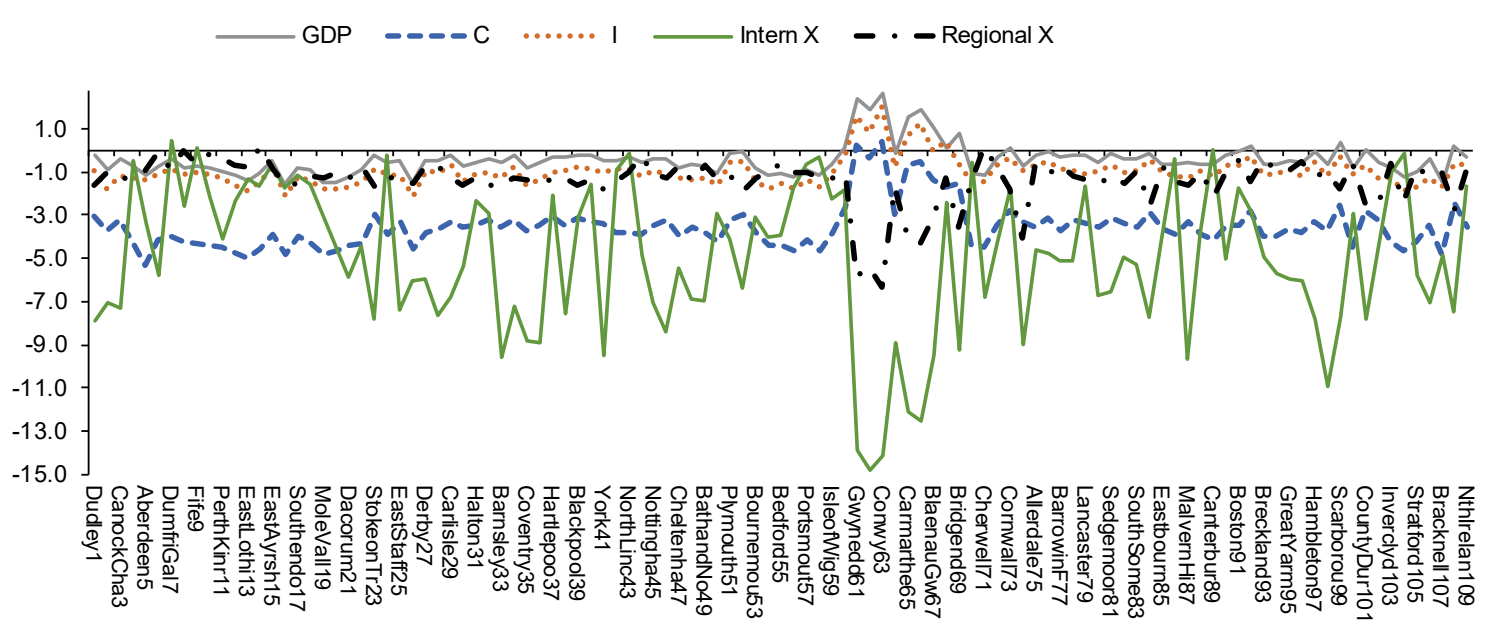

\section{Conclusion}

Prior to COVID-19 the UK faced a number of economic challenges in the short- to medium-term. Renegotiation of trading arrangements with the European Union was the most prominent of these. A second important medium-term challenge was the slowdown in productivity growth in the UK over the last two decades and the associated low overall labour productivity growth relative to other high-income countries. A third important challenge was the persistent and significant government budget deficit and corresponding accumulation of government debt.

These challenges have been analysed using the NiGEM model: a macroeconomic framework that is internally consistent, robust and built on micro-theoretic foundations (Hantzsche et al., 2018). NiGEM is a multi-country macroeconometic model of the global 
economy that is data driven in the short to medium term and neoclassical in the long term. We build on existing macroeconomic analysis of these challenges by projecting the effects on the UK's regions. The forecast scenario is generated by combining NiGEM with UK-SCGE, a regional computable general equilibrium of the UK.

The UK regional model is a dynamic CGE model with long-run properties similar to NiGEM. Short-run behaviour is mainly characterised by the movement from an initial steady-state that is consistent with the latest input-output data, and national and regional accounts. Over time the model slowly moves from the initial steady-state along a balanced growth path to a new steady-state. The version of the model applied here represents 29 industries and 109 regions. Like NiGEM, UK-SCGE includes a government sector with expenditure and revenue accounts, a representation of the current and capital accounts, accumulation of foreign assets, foreign liabilities, and government debt.

The NiGEM results are applied as annual inputs to the regional model. The inputs include expenditure-side components of GDP, labour supply, employment, labour hours, labour productivity, and consumer prices. This ensures that at the macro level the two models are consistent in their representation of the path of the aggregate economy. Using the macro inputs from NiGEM, the regional model generates a rich pattern of effects for 109 regions. These changes are decomposed to explain how regions are affected differentially by the various long-run trends in the UK economy that are projected by the macro model. Further, the regional results also provide a ranking of growth prospects across the UK regions. This ranking can provide policy makers with a view on where economic policy changes might be focussed to reduce the largest disparities in regional outcomes.

The central macroeconomic scenario shows a national average annual GDP growth rate of $1.7 \%$ over the period 2019-2044. When the macroeconomic forecasts are applied across regions growth rates range from $1.6 \%$ for Cambridge to $2.2 \%$ for Pembrokeshire. Despite wide variation at the extremes the standard deviation is low at $0.07 \%$ and the coefficient of variation is $0.04 \%$. The country results favour Scotland, which grows at annual rate of $1.8 \%$, whereas Wales is the slowest growing of the countries at $1.70 \%$.

Decomposing the forecasts we find that labour productivity is the most important contributor to the overall growth rate. Housing investment and export prices are the next most important contributors to the overall growth rate. Business investment makes the smallest contribution to the overall growth rate. While labour productivity is the most important contributor to the overall growth rate, it has a rather even effect on regional growth rates reflecting the even importance of labour shares in GDP across regions. There is much 
greater variation in the importance of exports in GDP. Thus, we find that movements in export prices cause the largest variations in regional growth rates.

Combining macro inputs from NiGEM with UK-SCGE generates a rich pattern of effects for 109 regions. The effects provide an internally consistent story of changes in regional output. The regional results also provide a ranking of growth prospects across the UK regions. This ranking can provide policy makers with a view on where economic policy changes might be focussed to reduce the largest disparities in regional outcomes. Our results suggest that policies focussed on improving productivity in regions with low growth prospects would reduce some of the unevenness in expected growth outcomes. 


\section{References}

Auerbach, A.J. (1982), 'The theory of excess burden and optimal taxation', Working paper 1025, National Bureau of Economic Research, Cambridge, Massachussetts.

Bargain, O., Orsini, K. and Peichl, A. (2011), 'Labour supply elasticities in Europe and the US', IZA Discussion Paper 5820, Bonn, June.

Behrens, K. and Mion, G. (2017), 'Estimating the costs and gains of TTIP and BREXIT for EU countries', PRONTO Research Network Working Papers.

Bell, D. and Blanchflower, D. (2018), 'The lack of wage growth and the falling NAIRU', National Institute Economic Review, vol. 245 (August), pp. R40-R55.

Douch, M., Edwards, T. H. and Soegaard, C. (2018), 'The trade effects of the Brexit announcement shock', Warwick Economics Research Papers, 1176.

Hanoch, G. (1971), 'CRESH production functions', Econometrica, vol. 39, no. 5, pp. 695712.

Hantzsche, A., Kara, A. and Young, G. (2018), 'Prospects for the UK economy', National Institute Economic Review, vol. 246 (November), pp. F4-F35.

Hantzsche, A., Kara, A. and Young, G. (2019), 'The economic effects of the UK government's proposed Brexit deal', The World Economy, vol. 42, issue 1, pp. 5-20.

Horridge, M. (2011), 'The TERM model and its data base', General Paper G-219, Centre of Policy Studies, July.

Jones, C., Coombes, M. and Wong, C. (2010), 'Geography of housing market areas', Department for Communities and Local Government.

Miller, R.E. and Blair, P.D. (2009), Input-output analysis: foundations and extensions (second edition), Cambridge University Press, Cambridge.

ONS (Office for National Statistics) (2019), Eurostat, An overview of the 3 NUTS and 2 LAU layers in the UK, https://www.ons.gov.uk/methodology/geography/ukgeographies/ eurostat.

ONS (2016), Input-Output Analytical Tables, 2013, London.

ONS (2010), Standard Occupational Classification, Volume 1 Structure and descriptions of unit groups, Palgrave Macmillan, Hampshire.

Stone, R. (1954), 'Linear expenditure systems and demand analysis: an application to the pattern of British demand', The Economic Journal, vol. 64, no. 255, pp. 511-527.

Vincent, D.P., Dixon, P.B. and Powell, A.A. (1980), 'The estimation of supply response in Australian agriculture: The CRESH/CRETH production system', International Economic Review, vol. 21, no. 1, pp. 221-42.

West, G.R. (1990), 'Regional trade estimation: a hybrid approach', International Regional Science Review, vol. 13, pp. 103-18. 


\section{Appendix 1 The UK-SCGE regions}

\section{Table A.1 The UK-SCGE regions}

\begin{tabular}{|c|c|}
\hline 1. Dudley & 56. Brighton and Hove \\
\hline 2. Birmingham & 57. Portsmouth \\
\hline 3. Cannock Chase & 58. Southampton \\
\hline 4. Babergh & 59. Isle of Wight \\
\hline 5. Aberdeen & 60. Isle of Anglesey \\
\hline 6. Scottish Borders & 61. Gwynedd \\
\hline 7. Dumfries Galloway & 62. Ceredigion \\
\hline 8. Anqus & 63. Conwy \\
\hline 9. Fife & 64. Shropshire \\
\hline 10. Eilean Siar & 65. Carmarthenshire \\
\hline 11. Perth \& Kinross & 66. Powys \\
\hline 12. Clackmannanshire & 67. Blaenau Gwent \\
\hline 13. East Lothian & 68. Pembrokeshire \\
\hline 14. East Dunbartonshire & 69. Bridgend \\
\hline 15. East Ayrshire & 70. Cambridgeshire \\
\hline 16. London & 71. Cherwell \\
\hline 17. Southend-on-Sea & 72. King's Lynn and West Norfolk \\
\hline 18. Medway & 73. Cornwall \\
\hline 19. Mole Valley & 74. Isles of Scilly \\
\hline 20. Guildford & 75. Allerdale \\
\hline 21. Dacorum & 76. Eden \\
\hline 22. East Hertfordshire & 77. Barrow-in-Furness \\
\hline 23. Stoke-on-Trent & 78. South Lakeland \\
\hline 24. Charnwood & 79. Lancaster \\
\hline 25. East Staffordshire & 80. East Devon \\
\hline 26. Cheshire East & 81. Sedgemoor \\
\hline 27. Derby & 82. North Devon \\
\hline 28. Leicester & 83. South Somerset \\
\hline 29. Carlisle & 84. West Dorset \\
\hline 30. Manchester & 85. Eastbourne \\
\hline 31. Halton & 86. Braintree \\
\hline 32. Cheshire West and Chester & 87. Malvern Hills \\
\hline 33. Barnsley & 88. Ashford \\
\hline 34. Doncaster & 89. Canterbury \\
\hline 35. Coventry & 90. Lincoln \\
\hline 36. Bradford & 91. Boston \\
\hline 37. Hartlepool & 92. East Lindsey \\
\hline 38. Blackburn with Darwen & 93. Breckland \\
\hline 39. Blackpool & 94. Forest Heath \\
\hline 40. East Riding of Yorshire & 95. Great Yarmouth \\
\hline 41. York & 96. Corby \\
\hline 42. North East Lincolnshire & 97. Hambleton \\
\hline 43. North Lincolnshire & 98. Ryedale \\
\hline 44. Rutland & 99. Scarborough \\
\hline 45. Nottingham & 100. Argyll \& Bute \\
\hline 46. Herefordshire & 101. County Durham \\
\hline 47. Cheltenham & 102. Gateshead \\
\hline 48. Telford and Wrekin & 103. Inverclyde \\
\hline 49. Bath and North East Somerset & 104. Hillingdon \\
\hline 50. Bristol & 105. Stratford-on-Avon \\
\hline 51. Plymouth & 106. Sunderland \\
\hline 52. Torbay & 107. Bracknell Forest \\
\hline 53. Bournemouth & 108. Northumberland \\
\hline 54. Swindon & 109. Northern Ireland \\
\hline 55. Bedford & \\
\hline
\end{tabular}




\section{Appendix 2 Implementing NiGEM forecasts in UK-SCGE}

In applying NiGEM forecasts to UK-SCGE, it necessary to accommodate the NiGEM outcomes within the theory of UK-SCGE if the relevant variable is endogenously determined. This describes the situation for most variables to which exogenous forecasts are applied.

\section{Household consumption.}

To impose a path of household consumption we set as endogenous the current account to GDP ratio path rather than imposing a path on it. This will mean that the household saving rate will adjust to allow household consumption to follow the path forecast by NiGEM.

Housing and business investment.

Sectoral investment is a function of the rate of return in UK-SCGE. To impose a path on housing investment we endogenise the intercept term for dwelling investment. To impose a path on business investment we endogenise the intercept term for non-dwelling investment.

\section{Government investment and consumption.}

Government investment and consumption are typically exogenous variables in UKSCGE. Therefore we are able to directly apply NiGEM forecast for these variables. Exports.

We apply a path on exports by endogenising the world export prices. $G D P$.

To impose a path on GDP we endogenise output per worker.

Population and labour supply.

Population is an exogenous variable in UK-SCGE. Therefore we are able to directly apply NiGEM forecast for population. Labour supply is typically determined by a labour supply function. To impose a path on labour supply we endogenise the intercept term.

Employment and labour hours.

Employment is typically determined by the interaction of labour demand and supply given an exogenous unemployment rate in UK-SCGE. To impose a path on employment we endogenous the unemployment rate. In UK-SCGE labour hours are a function of hours per worker and the number of workers (employment). To impose a path on labour hours we endogenise hours per worker, exogenise labour hours.

Consumer prices.

The consumer price index (CPI) is usually endogenous in the baseline of UK-SCGE. We make it exogenous and impose the NiGEM forecast and we make the exchange rate endogenous. 


\section{Government budget.}

In the baseline the ratio of the central government budget to GDP is typically exogenous and reduced by $2 \%$ per annum to ensure that government debt as share of GDP stabilises by the terminal year. The personal income tax rate adjusts to allow the path in budget balance to be achieved. Here we adjust the exogenous path in government to ensure it arrives in the terminal year consistent with the value observed in the NiGEM forecast. 